\title{
Padrão Nictemeral do pH Ruminal e Comportamento Alimentar de Cabras Leiteiras Alimentadas com Dietas Contendo Diferentes Relações Volumoso:Concentrado ${ }^{1}$
}

\author{
André Luigi Gonçalves ${ }^{2}$, Rogério de Paula Lana ${ }^{3}$, Marcelo Teixeira Rodrigues ${ }^{3}$, \\ Ricardo Augusto Mendonça Vieira ${ }^{4}$, Augusto César Queiroz ${ }^{3}$, Douglas Sampaio Henrique ${ }^{5}$
}

RESUMO - Os objetivos do presente estudo foram a caracterização do padrão nictemeral do pH ruminal e a avaliação do comportamento alimentar de cabras leiteiras alimentadas com dietas compostas por diferentes relações volumoso:concentrado. Foram utilizadas cinco cabras, com peso médio de $58 \mathrm{~kg}$, não-lactantes, não-gestantes, fistuladas no rúmen, em cinco períodos experimentais. Cada animal foi observado em cada um dos cinco tratamentos, que consistiram das relações volumoso:concentrado de 100:0, 80:20, 60:40, 40:60 e 20:80, em um delineamento em quadrado latino $5 \times 5$. As dietas foram fornecidas a cada 6 horas, buscando amenizar a variação dos níveis de $\mathrm{pH}$ ruminal, durante o período de 24 horas, para todos os tratamentos. Após a adaptação dos animais às dietas experimentais, estes foram observados por um período de 48 horas, no qual foi mensurado o pH ruminal a cada hora, bem como em outro período de mesma duração, em que se observou o comportamento a cada 10 minutos. Foi constatado que o nível de concentrado crescente resultou em decréscimo sobre o $\mathrm{pH}$, cujos valores decresceram mais drasticamente em níveis acima de 60\%. Observou-se também o efeito de tratamento sobre tempo de alimentação, ruminação e ócio. O tempo de alimentação foi maior para as dietas contendo valores acima de $60 \%$ de volumoso. A dieta contendo $100 \%$ de volumoso apresentou maior tempo de ruminação e menor ócio, seguida das dietas contendo 80 e $60 \%$ de volumoso, enquanto aquelas contendo 40 e $20 \%$ apresentaram menor tempo de ruminação e maior ócio.

Palavras-chave: caprinos, etologia, $\mathrm{pH}$ ruminal, fibra

\section{Nictemeral Pattern of Ruminal pH and Feeding Behavior of Dairy Goats Fed Diets with Different Roughage to Concentrate Ratio}

\begin{abstract}
The objectives of the present study were to characterize nictemeral pattern of ruminal $\mathrm{pH}$ and feed behavior of dairy goats fed diets presenting different ratios of roughage:concentrate. Five non pregnant non lactating goats, ruminally cannulated, and averaging $58 \mathrm{~kg}$ were used during the five experimental periods. A $5 \times 5$ Latin square was used to evaluate five treatments consisted of roughage to concentrate ratio of 100:0, 80:20, 60:40, 40:60 e 20:80. Diets were fed every $6 \mathrm{~h}$ in order to reduce ruminal pH variation during the $24 \mathrm{~h}$ period. After adaptation to experimental diets, a $48 \mathrm{~h}$ period was given to measure ruminal $\mathrm{pH}$ hourly for $24 \mathrm{~h}$, to be used as a covariate, following a study of feeding behavior where measurement was taken at every 10 minutes for the remaining $24 \mathrm{~h}$ period. It was observed that increasing level of concentrate resulted in reduction of $\mathrm{pH}$, especially when concentrate accounted for more than $60 \%$. Treatment effect was also observed on time spent eating, ruminating and idling. Time spent eating was greater as percentage of roughage in the diet increased, especially over $60 \%$. Roughage content of $100 \%$ presented the highest value of rumination time and the lowest value for idle, following diets containing 80 e $60 \%$ respectively. There were no difference between diets containing 40 e $20 \%$ roughage, which presented the lowest value for rumination and the highest for idle time.
\end{abstract}

Key Words: goats, etology, ruminal $\mathrm{pH}$, fiber

\section{Introdução}

Animais de alta produção apresentam maior exigência em nutrientes, particularmente de energia, para suportar os elevados índices de produtividade. A alimentação desses animais, baseada em volumosos, torna-se limitante, uma vez que estes alimentos apresentam baixa concentração em nutrientes por unidade de massa e, ainda, lenta taxa de degradação e escape, restringindo, por conseguinte, a ingestão. $\mathrm{O}$ consumo voluntário de forragem é um ponto crítico determinante do desempenho animal, e a concentração de parede celular tem sido relacionada negativamente à ingestão de alimentos por ruminantes consumindo dietas com elevados níveis de forragem (JUNG e ALLEN, 1995).

Dessa forma, torna-se necessária a inclusão de alimentos concentrados para o atendimento das exi-

\footnotetext{
1 Parte da tese de Mestrado apresentada à UFV para obtenção do título "Magister Scientiae".

${ }^{2}$ Mestre em Zootecnia/PROCABRA-UFV. E.mail: luigi@mail.ufv.br

3 Professor da UFV. Bolsita do CNPq.

${ }^{4}$ Professor da UEG; Pesquisador do Instituto Melon, Silvânia - GO.

${ }^{5}$ Estudante de graduação/UFV.
} 
gências nutricionais, o que implica na redução da proporção de volumosos na dieta. Entretanto, quando se aumenta o teor de concentrados, podem aparecer distúrbios digestivos que comprometem a saúde animal, levando à redução do desempenho produtivo (MERTENS, 1997).

$\mathrm{O}$ pH ruminal é influenciado pelo tipo de alimento consumido e sua estabilização é atribuída, em grande parte, à saliva, que possui alto poder tamponante (OWENS e GOETSCH, 1988; VAN SOEST, 1994). A saliva sofre incremento em seu fluxo, devido ao estímulo da mastigação e ruminação, que resulta de reflexos iniciados por estímulos físicos das partículas grosseiras sobre a parede ruminal (HARFOOT, 1981; HOOVER E STOKES, 1991).

A redução do $\mathrm{pH}$ ruminal ocorre, principalmente, após a rápida digestão do alimento, em virtude de elevadas taxas de degradação, atingindo seu menor valor entre 0,5 e 4 horas após a alimentação (ØRSKOV, 1986). O fornecimento de grãos de cereais moídos acarreta alguns problemas, entre os quais se encontra a inadequada secreção de saliva para manter o $\mathrm{pH}$ entre 6 e 7, bem como a imprópria estrutura física para estimular a motilidade ruminal.

A redução do $\mathrm{pH}$ diminui a digestão da proteína, celulose, hemicelulose e pectina, tendo menor efeito sobre a digestão do amido (HOOVER e STOKES, 1991). Estudos in vitro indicam que a eficiência de síntese de proteína microbiana pode diminuir, quando o pH é menor que 6 (STROBEL e RUSSELL, 1986).

ØRSKOV (1988) relatou que, em situações de $\mathrm{pH}$ abaixo de 6,2, ocorreu redução na digestão da fibra, devido à sensibilidade das bactérias fibrolíticas, e o ponto ótimo da digestão da fibra ocorre em valores de pH entre 6,7 e 7,1. Esta informação é importante, uma vez que não tem sido enfatizado o efeito do $\mathrm{pH}$ sobre a fermentação da fibra nas técnicas in vitro, contrariando as condições predominantes no rúmen-retículo.

Os períodos de tempo gastos com a ingestão de alimentos são intercalados com um ou mais períodos de ruminação ou de ócio. O tempo gasto em ruminação é mais elevado à noite, mas os períodos de ruminação são ritmados também pelo fornecimento de alimento. Entretanto, existem diferenças entre indivíduos quanto à duração e à repartição das atividades de ingestão e ruminação, que parecem estar relacionadas ao apetite dos animais, a diferenças anatômicas e ao suprimento das exigências energéticas ou repleção ruminal, que seriam influenciadas pela relação volumoso:concentrado (FISCHER, 1998)
Buscou-se como objetivos do presente trabalho avaliar a influência de níveis crescentes da relação volumoso:concentrado sobre o $\mathrm{pH}$ ruminal, bem como traçar o padrão nictemeral desta variação e o comportamento alimentar de cabras leiteiras.

\section{Material e Métodos}

O presente trabalho foi realizado no Setor de Caprinocultura e no Laboratório de Nutrição Animal do Departamento de Zootecnia da Universidade Federal de Viçosa, no período de julho de 1998 a março de 1999.

Foram utilizadas cinco cabras da raça Alpina, com peso médio de $58 \mathrm{~kg}$, não-prenhes, não-lactantes e fistuladas no rúmen. As cabras foram alojadas em baias individuais de alvenaria, medindo $1,75 \mathrm{~m} \times 1,20 \mathrm{~m}$, com piso ripado em madeira, disponibilidade irrestrita de água e sal mineral e cocho ocupando $0,80 \mathrm{~m}$ da parte frontal, disposto centralmente.

Utilizou-se o delineamento estatístico em quadrado latino $5 \times 5$. As análises estatísticas dos dados foram realizadas utilizando o programa SAEG - Sistema de Análise Estatística e Genética (UNIVERSIDADE FEDERAL DE VIÇOSA - UFV, 2000), bem como a determinação das equações de regressão. $\mathrm{O}$ modelo utilizado foi:

$$
\mathrm{Y}_{\mathrm{ijk}}=\mu+\mathrm{T}_{\mathrm{i}}+\mathrm{C}_{\mathrm{j}}+\mathrm{P}_{\mathrm{k}}+\mathrm{e}_{\mathrm{ijk}}
$$

em que: $\mu$ é a média geral, $\mathrm{T}_{\mathrm{i}}$, o efeito do i-ésimo tratamento; $\mathrm{C}_{\mathrm{j}}$, o efeito do $\mathrm{j}$-ésimo animal, $\mathrm{P}_{\mathrm{k}}$, o efeito do k-ésimo período; e $\mathrm{e}_{\mathrm{ijk}}$, o erro experimental.

Os animais receberam as dietas em mistura completa a cada 6 horas, para padronizar os intervalos das alimentações e possibilitar a caracterização da flutuação do $\mathrm{pH}$ ruminal.

As dietas foram isoprotéicas (12\% PB), com níveis crescentes de concentrado (Tabela 1). As dietas foram pesadas antes do oferecimento e, semanalmente, o fornecimento, ajustado e as sobras, pesadas, buscando não haver mais de $10 \%$ de sobra nos cochos. Cada período experimental consistiu-se de 15 dias.

O comportamento alimentar dos animais nas baias foi determinado pela quantificação dos intervalos de tempo em que os animais se encontravam nas fases de alimentação, ruminação e ócio, o que totalizou 144 observações em 24 horas. Estes dados foram analisados de acordo com o modelo descrito anteriormente, sendo o efeito de tratamento decomposto nos componentes linear, quadrático e cúbico, testados por meio de análise de variância. 
Tabela 1 - Composição das dietas experimentais, com base na matéria seca

Table 1 - Composition of experimental diets, on dry matter basis

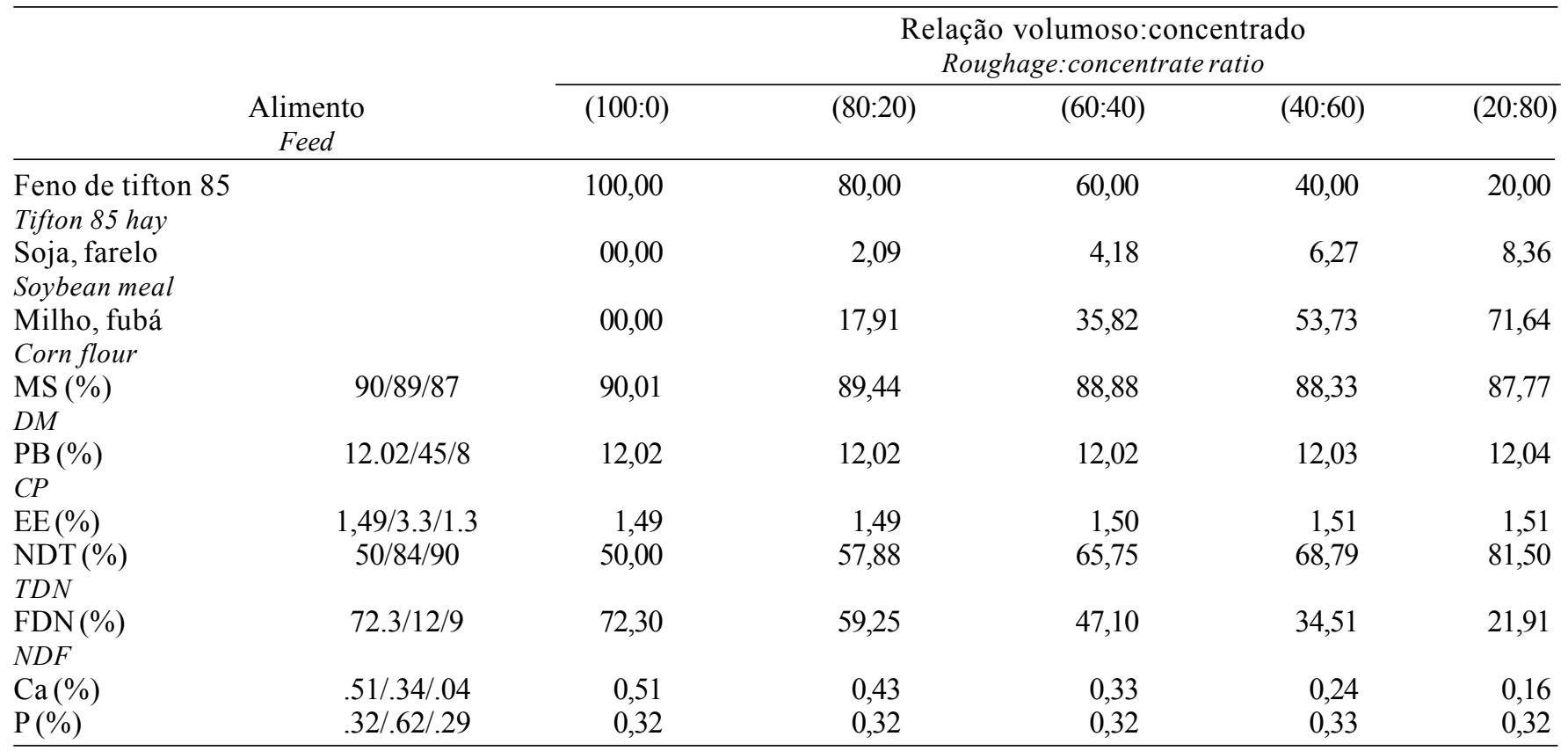

O perfil nictemeral de variação do $\mathrm{pH}$ foi determinado por meio da medição do $\mathrm{pH}$ ruminal a cada hora, imediatamente após o fornecimento da alimentação, por um período de 24 horas. A interpretação dos perfis foi efetuada por meio de séries temporais para caracterização das alterações do $\mathrm{pH}$ ao longo do dia. Foi empregado o seguinte modelo:

$$
\begin{gathered}
Y_{i j}=A_{0}+A_{1} \times \operatorname{sen}\left(C_{i j}\right)+A_{2} \times \cos \left(C_{i j}\right)+A_{3} \times \\
\quad \operatorname{sen}\left(2 \mathrm{CT}_{i j}\right)+A_{4} \times \cos \left(2 C_{i j}\right)
\end{gathered}
$$

em que: $Y_{i j}$ representa o potencial hidrogeniônico no tempo $t_{i}$; $\mathrm{C}$, uma fração constante do período fundamental, que corresponde a $\pi$ radianos. $\mathrm{h}^{-1} ; \mathrm{T}_{\mathrm{ij}}$, o tempo em horas; $\mathrm{A}_{0}$, o valor médio de $\mathrm{pH}$; e $\mathrm{A}_{1}$ a $\mathrm{A}_{4}$, as amplitudes dos picos e vales dos ciclos. $\mathrm{O}$ valor de $\mathrm{C}$, sendo circadiano, é fixado em 0,1309 radianos por hora, correspondendo a 24 horas de um período fundamental (HOPPER et al., 1978). O valor da constante C para o presente trabalho foi calculado em 0,5236 .

\section{Resultados e Discussão}

A utilização de concentrados na alimentação de cabras leiteiras tem acarretado incremento significativo, em função do aumento de produtividade, o que, de certa forma, se contrapõe à característica principal dos ruminantes, que é a degradação de componentes da fibra dos alimentos, pela presença de microrganismos ruminais. A cabra, conforme defini- ção de Hoffmamn, é um ruminante intermediário, entre selecionadores de alimentos concentrados e pastejadores, ou seja, busca na planta, por uma questão de seleção natural, as partes em que há maior concentração de nutrientes, em detrimento de outras partes mais fibrosas. Dessa forma, em condições naturais, alimenta-se de brotos, folhas de leguminosas, grãos, entre outros (VAN SOEST, 1994). Em virtude desta característica, fisiologicamente, a cabra apresenta maior taxa de passagem das partículas do alimento pelo trato gastrintestinal (VAN SOEST, 1987), o que pressupõe menor eficiência de degradação da fibra alimentar. Isto demonstra um processo de adaptabilidade ao meio, uma vez que estes animais, para sobreviverem à ação de seus predadores, não se expunham em pastejo, adaptando-se à seleção, principalmente, de pequenos arbustos.

Redução na relação volumoso:concentrado impõe condições aos animais que implicam modificação de seu comportamento, bem como do ambiente ruminal. Segundo MERTENS et al. (1997), os animais ruminantes requerem teor mínimo de fibra em sua dieta, para oferecer estímulo ruminal, de tal sorte que, em seus movimentos e contrações, permite ao animal o movimento antiperistáltico do esôfago, levando o bolo alimentar novamente a boca, onde o bolo alimentar sofre remastigação e estimula a liberação de saliva, que apresenta ação tamponante no rúmen, 
em virtude da concentração de bicarbonato presente em sua constituição.

Dessa forma, além da mudança de ordem fisiológica esperada, podem-se, também, observar outras de ordem comportamental, que constam da Figura 1.

Animais alimentados com dietas variando entre 0 e $40 \%$ de concentrado apresentaram valores relativamente próximos para os tempos dedicados à alimentação, ruminação e ócio (Figura 1). Nota-se, nitidamente, redução no tempo de alimentação e, mais acentuadamente, no de ruminação, à medida que se elevou o concentrado na dieta. Em termos de distribuição do tempo, em horas por dia, evidenciase, na Figura 2, que, após aplicada a análise de variância e usado um modelo de regressão, em todos os casos foram observados efeitos lineares, o que demonstrou a existência de correlação entre o teor de concentrado na dieta e o comportamento alimentar destes animais.

Observou-se que o aumento do nível de concentrado nas dietas resultou em menores tempos de alimentação e ruminação, em função da elevada densidade energética da dieta; conseqüentemente, foi maior o tempo de ócio. Isto se deve ao fato de a baixa concentração de fibra dietética não ter estimulado a ruminação (VAN SOEST, 1987). Pode-se inferir, por conseguinte, que, com a diminuição da ruminação, a ensalivação deverá ser reduzida, o que

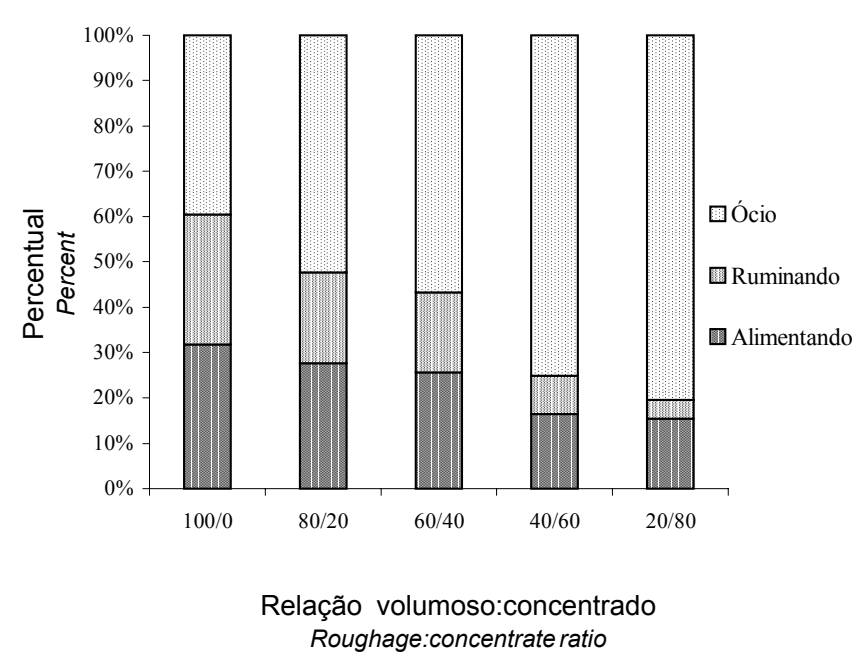

Figura 1 - Comportamento alimentar de cabras leiteiras submetidas a diferentes relações volumoso: concentrado, em valores porcentuais, no período de 24 horas.

Figure 1 - Feeding behavior of dairy goats fed different roughage:concentrate ratio (\%), in a 24-h period. implica na não-manutenção das condições ruminais e, principalmente, na redução das bactérias fibrolíticas, o que provoca mudanças bastante significativas no processo digestório, como a produção acentuada de ácido lático e acidose subclínica, entre outros distúrbios metabólicos. Todavia, os caprinos apresentam maior capacidade de consumo de concentrado que outros ruminantes, pois adaptaram-se a esta condição durante seu processo evolutivo (GIHAD et al., 1980).

Após a tentativa de ajuste de um modelo destinado à descrição de perfis de séries temporais, verificou-se que, em dietas exclusivamente volumosas, não houve alterações no $\mathrm{pH}$ que pudessem ser explicadas pelo modelo descrito na Equação 2 (Tabela 2; Figura 3). Nota-se uma dispersão dos pontos totalmente aleatória, o que faz com que a equação estabeleça quase uma reta, entremeada pela nuvem de pontos. Contudo, o ajuste para os níveis de concentrado demonstrou, gradativamente, progressiva adequação do modelo aos dados observados, em função do aumento dos teores de concentrado, com picos e vales bem caracterizados. $\mathrm{O}$ pH atingiu seu ponto mínimo entre 2 e 4 horas após cada alimentação, possivelmente devido à maior taxa de produção de ácidos graxos voláteis, provenientes da fermentação da fração não-fibrosa do alimento (VAN SOEST, 1994), o que coincide com valores observados por ØRSKOV (1986).

Observou-se que a capacidade de tamponamento das cabras submetidas ao tratamento com fornecimento exclusivo de volumoso foi extremamente eficiente, não havendo efetivamente qualquer tendência de oscilação. A tendência predita pelo modelo pode ser vista na Figura 3, em que se obteve, pela dispersão acentuada dos pontos, $\mathrm{r}^{2}$ de 0,03 , o que efetivamente não pode ser interpretado como comportamento periódico.

Os demais tratamentos apresentaram aumento gradativo no grau de explicação da variação observada nos perfis pelo ajuste do modelo, à medida que se diminuiu o nível da forragem na dieta. Contudo, estes valores são baixos para que o modelo explique os pontos obtidos $\left(\mathrm{r}^{2}=0,04 ; 0,08 ; 0,23\right.$; e 0,44 , respectivamente, para as relações volumoso:concentrado 80:20, 60:40, 40:60 e 20:80). Talvez, se a alimentação fosse oferecida em condições de manejo convencional, ou seja, duas vezes ao dia, houvesse maior delimitação dos ciclos, caracterizando melhor o padrão, como o observado em ovinos por FISCHER et al (1998), uma vez que os períodos de ruminação são afetados também pela oferta dos alimentos. 
Tabela 2 - Equações obtidas a partir do modelo de série temporal, por tratamento

Table 2 - Equations obtained from a time serie model, by treatment

\begin{tabular}{lcc}
$\begin{array}{l}\text { Tratamento }^{1} \\
\text { Treatment }\end{array}$ & $\begin{array}{l}\text { Regressão } \\
\text { Regression }\end{array}$ & $\mathrm{R}^{2}$ \\
\hline $100: 0$ & $\mathrm{Y}=7,13+0,0063 \operatorname{sen}\left(\mathrm{CT}_{\mathrm{ij}}\right)+0,0059 \cos \left(\mathrm{CT}_{\mathrm{ij}}\right)+0,0099 \operatorname{sen}\left(2 \times \mathrm{CT}_{\mathrm{ij}}\right)-0,0018 \cos \left(2 \times \mathrm{CT}_{\mathrm{ij}}\right)$ & 0,03 \\
$80: 20$ & $\mathrm{Y}=6,68+0,0002 \operatorname{sen}\left(\mathrm{CT}_{\mathrm{ij}}\right)+0,0023 \cos \left(\mathrm{CT}_{\mathrm{ij}}\right)-0,004 \operatorname{sen}\left(2 \times \mathrm{CT}_{\mathrm{ij}}\right)+0,0346 \cos \left(2 \times \mathrm{CT}_{\mathrm{ij}}\right)$ & 0,04 \\
$60: 40$ & $\mathrm{Y}=6,57-0,0123 \operatorname{sen}\left(\mathrm{CT}_{\mathrm{ij}}\right)+0,0084 \cos \left(\mathrm{CT}_{\mathrm{ij}}\right)-0,0160 \operatorname{sen}\left(2 \times \mathrm{CT}_{\mathrm{ij}}\right)+0,0586 \cos \left(2 \times \mathrm{CT}_{\mathrm{ij}}\right)$ & 0,08 \\
$40: 60$ & $\mathrm{Y}=6,09+0,0096 \operatorname{sen}\left(\mathrm{CT}_{\mathrm{ij}}\right)+0,0162 \cos \left(\mathrm{CT}_{\mathrm{ij}}\right)-0,0317 \operatorname{sen}\left(2 \times \mathrm{CT}_{\mathrm{ij}}\right)+0,0507 \cos \left(2 \times \mathrm{CT}_{\mathrm{ij}}\right)$ & 0,23 \\
$20: 80$ & $\mathrm{Y}=5,75-0,0080 \operatorname{sen}\left(\mathrm{CT}_{\mathrm{ij}}\right)-0,0135 \cos \left(\mathrm{CT}_{\mathrm{ij}}\right)-0,0001 \operatorname{sen}\left(2 \times \mathrm{CT}_{\mathrm{ij}}\right)+0,0568 \cos \left(2 \times \mathrm{CT}_{\mathrm{ij}}\right)$ & 0,44 \\
\hline
\end{tabular}

${ }^{1}$ Relação volumoso:concentrado.

${ }^{1}$ Roughage:concentrate ratio.

A variação de $\mathrm{pH}$ observada durante o período de 24 horas para cada tratamento foi analisada com base nas médias por tratamento, em cada interação animal $\times$ período. Foi observado decréscimo quadrático $(\mathrm{P}<0,05)$ do nível de concentrado sobre o $\mathrm{pH}$ ruminal (Figura 4), o que pode ser explicado pela menor atividade de ruminação observada para estes tratamentos, que induz à redução da secreção salivar, importante na manutenção da atividade tamponante, responsável pelo controle do $\mathrm{pH}$ ruminal (VAN SOEST, 1994).

Da mesma forma, verificou-se que o consumo de matéria seca (CMS), bem como de fibra em detergente neutro (CFDN), foi influenciado pela relação volumoso:concentrado, conforme pode ser observado na Tabela 3. Avaliando-se estes valores, observa-se que, na busca do atendimento nutricional, tenha havido controle fisiológico, limitando o consumo, ao ser atingido o requerimento energético, uma vez que os animais alimentados com dieta contendo maior teor de concentrado apresentaram menor consumo. Por outro lado, a maior ingestão em valores absolutos, bem como em termos percentuais do peso vivo, sugere não ter havido limitação física, já que os

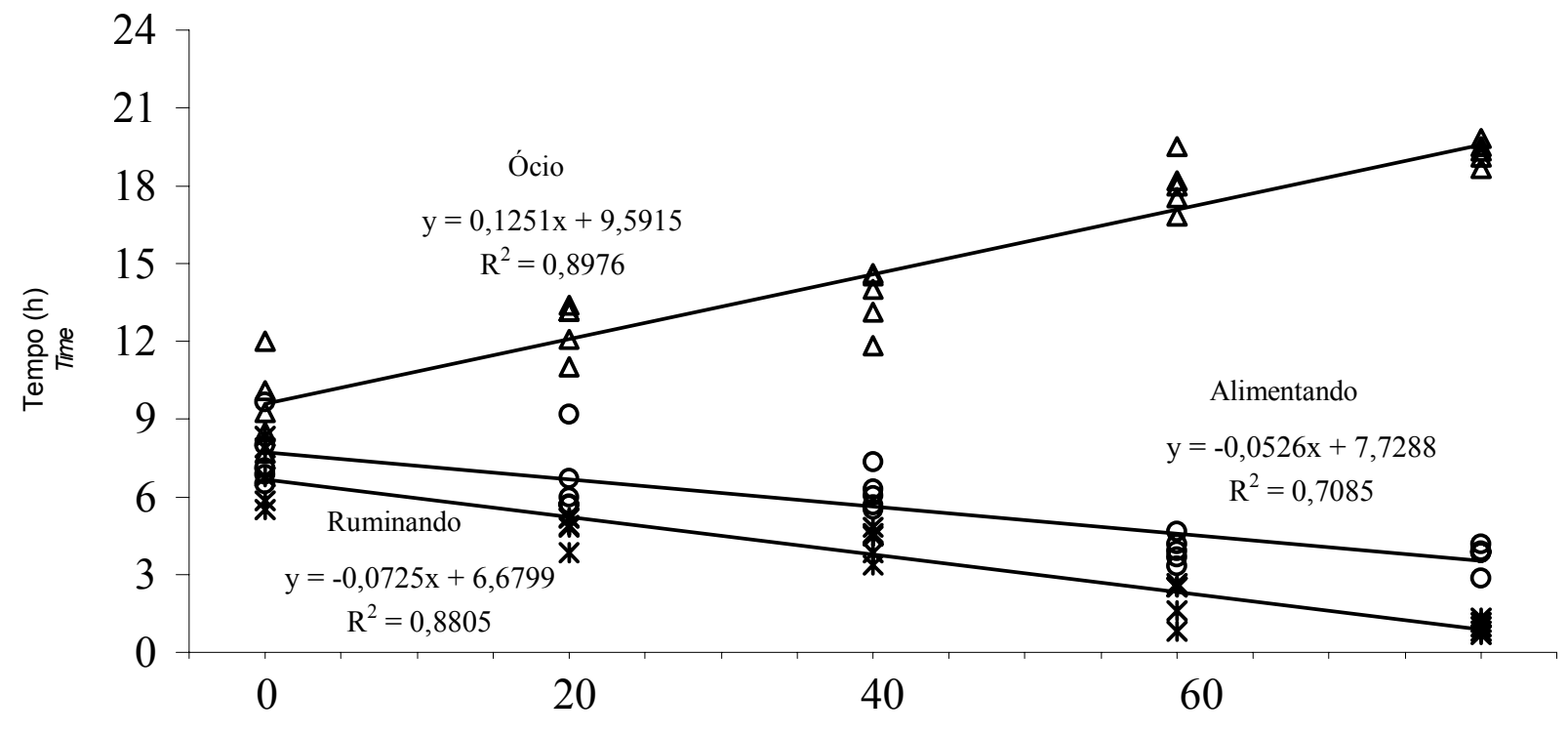

Nível de concentrado na dieta (\%)

Concentrate level in the diet

Figura 2 - Equações de regressão para o comportamento alimentar, em cabras leiteiras em diferentes relações volumoso:concentrado.

Figure 2 - Regression equations for feeding behavior of dairy goats fed different roughage:concentrate ratio. 


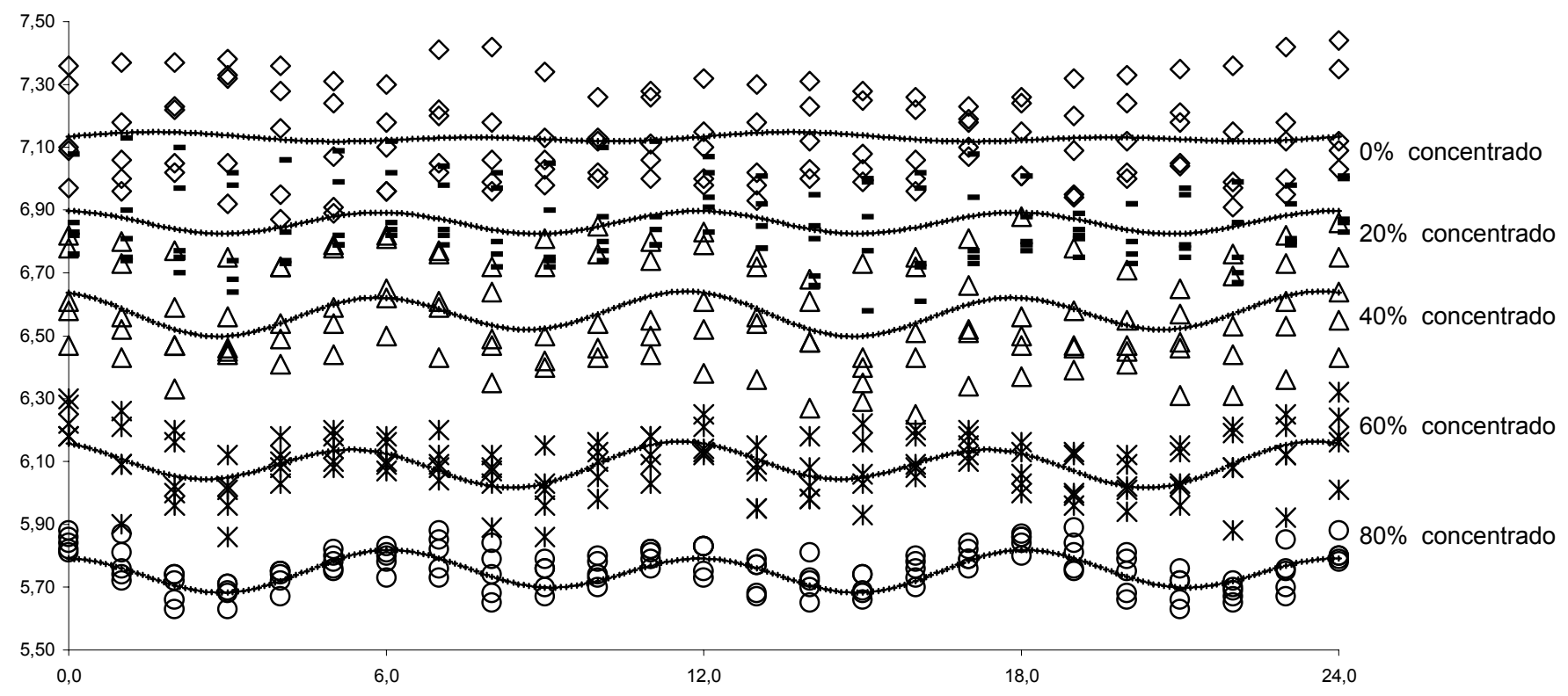

Figura 3 - Dispersão dos pontos, por tratamento (0, 20, 40, 60 e 80\% de concentrado na dieta), e curvas do padrão nictemeral do $\mathrm{pH}$ ruminal, determinadas pelo método de série temporal.

Figure 3 - Points dispersion, by treatment (0,20, 40,60 and $80 \%$ of concentrate in the diet), and nycterohemeral pattern curves of ruminal $\mathrm{pH}$, determined by the time serie method.

animais não atingiram estádio de repleção ruminal.

O consumo de FDN neste experimento sugere que, para caprinos, os valores observados por MERTENS (1987, 1988 e 1997), para bovinos, não são aplicáveis, uma vez que os animais, apesar de não estarem em lactação, porém ingerindo alimentação exclusivamente volumosa, chegaram a consumir valores 2,5 vezes maiores que os preconizados por aquele autor. Este fato pode ser justificado por maior taxa de passagem observada em caprinos, como as relatadas por SILANIKOVE et al. (1993), que observaram

Tabela 3 - Consumo médio diário de matéria seca (CMS) e fibra em detergente neutro (CFDN), em $\mathrm{kg} \mathrm{e}$ porcentual do peso vivo (\%PV)

Table 3 - Average daily intake of dry matter (DMI) and neutral detergent fiber (NDFl), in $\mathrm{kg}$ and \% live weight (\%LW)

\begin{tabular}{lcccc}
\hline Relação V:C & $\begin{array}{c}\text { CMS } \\
\text { R:C ratio }\end{array}$ & $\begin{array}{c}\text { CMS } \\
(\% \mathrm{PV})\end{array}$ & $\begin{array}{c}\text { CFDN } \\
(\mathrm{kg})\end{array}$ & $\begin{array}{c}\text { CFDN } \\
(\% \mathrm{PV})\end{array}$ \\
& $\begin{array}{c}D M I \\
(\mathrm{~kg})\end{array}$ & $\begin{array}{c}\text { NDFI } \\
(\% L W)\end{array}$ & $\begin{array}{c}D M I \\
(\mathrm{~kg})\end{array}$ & $\begin{array}{c}\text { NDFI } \\
(\% L W)\end{array}$ \\
\hline $100: 0$ & 2,39 & 4,12 & 1,73 & 2,98 \\
$80: 20$ & 2,35 & 4,05 & 1,34 & 2,31 \\
$60: 40$ & 2,33 & 4,01 & 1,01 & 1,74 \\
$40: 60$ & 2,24 & 3,87 & 0,65 & 1,12 \\
$20: 80$ & 2,07 & 3,57 & 0,30 & 0,52 \\
\hline
\end{tabular}

em animais da raça Saanen, em condições semelhantes às apresentadas neste experimento, valores na ordem de $3,164 \% / \mathrm{h}$. Outro fator favorável por este maior consumo poderia ser o fracionamento do fornecimento da dieta em quatro refeições diárias.

As análises de variâncias decompostas em polinômios ortogonais possibilitaram a obtenção das equações, conforme a Tabela 4, que demonstram, por meio de regressões, nítida influência na relação volumoso:concentrado sobre a ingestão de MS e FDN.

Tabela 4 - Modelo de regressão obtido pela análise de variância para CMS e CFDN, em kg e porcentual do peso vivo

Table 4 - Regression model obtained by the analysis of variance for DMI and NDFI, in $\mathrm{kg}$ and \% live weight (\%LW)

\begin{tabular}{llcc}
\hline & $\begin{array}{c}\text { Equação de regressão } \\
\text { Regression equation }\end{array}$ & $\mathrm{r}^{2}$ & $\mathrm{CV}$ \\
\hline CMS $(\mathrm{kg})$ & $\mathrm{y}=-0,0038 \mathrm{x}+2,426$ & 0,86 & 2,51 \\
$\begin{array}{l}\text { DMI }(\mathrm{kg}) \\
\text { CMS }(\% \mathrm{PV})\end{array}$ & $\mathrm{y}=-0,0064 \mathrm{x}+4,18$ & 0,86 & 3,29 \\
$\begin{array}{l}\text { DMI }(\% L W) \\
\text { CFDN }(\mathrm{kg})\end{array}$ & $\mathrm{y}=-0,0177 \mathrm{x}+1,7153$ & 0,99 & 2,48 \\
NDFI $(\mathrm{kg})$ & & & \\
CFDN $(\% \mathrm{PV})$ & $\mathrm{y}=-0,0306 \mathrm{x}+2,956$ & 0,99 & 2,84 \\
NDFI $(\% L W)$ & & & \\
\hline
\end{tabular}




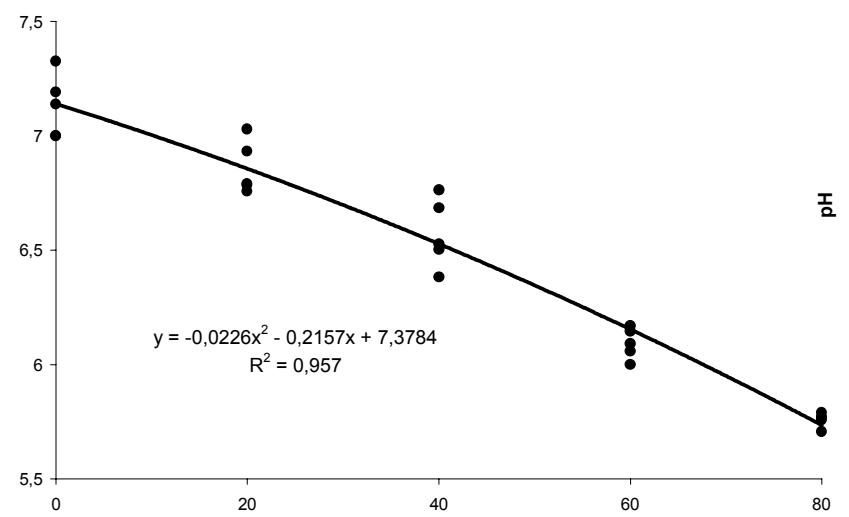

Nível de concentrado (\%)

Concentrate of level (\%)

Figura 4 - Equação de regressão estimada e valores observados do $\mathrm{pH}$ ruminal, em função da relação volumoso:concentrado.

Figure 4 - Estimated regression equation and $\mathrm{pH}$ ruminal observed values, in function of different roughage:concentrate ratio.

\section{Conclusões}

O aumento do nível de concentrado resultou na definição gradual de uma periodização no perfil nictemeral do $\mathrm{pH}$ ruminal das cabras. Este incremento reduziu o tempo dedicado ao consumo de matéria seca e à ruminação, em função dos menores teores de fibra, para estimular as funções ruminais, e prolongou a ociosidade, pela maior densidade energética da dieta, o que aumentou o período da saciedade dos animais.

\section{Referências Bibliográficas}

FISCHER, V., DESWYSEN, A.G., DÈPRES, L. et al. 1998. Padroes nectemerais do comportamento ingestivo de ovinos. R. Bras. Zootec., 27(2):362-369.

GIHAD, E.A., EL-BDAWY, T.M., MEHRREZ, A.Z., 1980. Fiber digestibility by goats and sheep. J. Dairy Sci., 63(10)1701-1706.

HARFOOT, C.G. 1981. Anatomy physiology and microbiology of the ruminant digestive tract. In: CHRISTIE, W.W. (Ed.) Lipid metabolism in ruminant animals. New York: Pergamon Press Inc. p.1-19.

HOOVER, W.H., STOKES, S.R. 1991. Balancing carbohydrate and proteins for optimum rumen microbial yield. J. Dairy Sci., 74(10):3630-3644.

HOPPER J.T., HOLLOWAY, J.W., BUTTS JR., W.T. 1978. Animal variation in chromium sesquioxide excretion patterns of grazing cows. J. Anim. Sci., 46(4):1096-1102.
JUNG, H.G., ALLEN, M.S. 1995. Characteristics of plant cell walls affeting intake and digestibility of forages by ruminants. J. Anim. Sci., 73(7):2774-2790.

MERTENS, D.R. 1987. Predicting in intake and digestibility using mathematical models of ruminal functions. J. Anim. Sci., 64(5):1548-1558.

MERTENS, D.R. Balancing Carbohydrates in dairy rations. In: LARGE HERD DAIRY MANAGEMENT CONFERENCE, Ithaca, 1995. Proceedings... Ithaca: Cornell University: Department of Animal Science, Cornell, 1988. p.150-161.

MERTENS, D.R. 1997. Creating a system for meeting the fiber requirements of dairy cows. J. Dairy Sci., 80(5):1463-1481.

OWENS, F.N., GOETSCH, A.L. 1988. Ruminal fermentation. In: $\mathrm{CHURCH}$, D.C. The ruminant animal digestive physiology and nutrition. Englewood Cliffs: O. \& Books Inc. p.146-171.

ØRSKOV, E.R. 1986. Starch digestion and utilization in ruminants. J. Anim. Sci., 63(5):1624-1633.

ØRSKOV, E.R. 1988. Nutricion proteica de los ruminantes. Saragoza: Ed. Acribia. 178p.

SILANIKOVE, N., TAGARI, H., SHKOLNIK, A. 1993. Comparison of rate of passage, fermentation rate and efficiency of digestion of high fiber diet in desert Bedouin goats compared to Swiss Saanen goats. Small Rum. Res., 12(1):45-60.

STROBEL, H.J., RUSSELL, J.B. 1986. Effect of pH and energy spilling on bacterial protein syntheses by carbohydrate limited cultures of mixed rumen bacteria. J. Dairy Sci., 69(10):2947-2959.

UNIVERSIDADE FEDERAL DE VIÇOSA - UFV. 2000. SAEG - Sistema de análises estatísticas e genéticas. Versão 8.0. Viçosa, MG. 142p. (Manual do usuário).

VAN SOEST, P.J. Interactions of feeding behavior and forage composition. In: INTERNATIONAL CONFERENCE ON GOATS, 4, 1987, Brasília. Proceedings ... Brasília, 1987, p.971-87.

VAN SOEST, P.J. 1994. Nutritional ecology of the ruminant. 2.ed. Ithaca: Cornell University Press. 476p. 